\title{
Increase in hospitalisation for childhood asthma
}

\section{H. ROSS ANDERSON}

From the Department of Clinical Epidemiology and Social Medicine, St. George's Hospital Medical School, London

SUMMARY Asthma admissions among children under 15 years of age have increased nearly threefold over the period 1959-73. The possible reasons for this increase have been examined using available data supplemented by the results of a special study of hospital disease indexes and case notes. Changes in diagnostic coding and trends in diagnostic fashion do not appear to be important. Part of the increase may be due to an increase in readmission rates. Changes in admission criteria resulting from changes in therapy, organisation of care, and illness behaviour have been considered. However, on present evidence an increase in morbidity cannot be excluded, and this could be investigated by repeat prevalence surveys of schoolchildren. If morbidity remains unchanged, admission policies for children with asthma should be reviewed.

The Hospital In-Patient Enquiry (HIPE, Department of Health and Social Security) shows that the annual admission* rate for asthma in children aged 1-14 years has increased nearly threefold over the 15-year period to 1973 (Fig. 1). Among the 5- to 14year age group, in 1972 asthma accounted for nearly twice as many bed-days as bronchitis and pneumonia combined, a reversal of the situation in 1960 (Table 1). Similar trends have been reported from Scotland (Lockwood, 1971) and from three different parts of the United States (Richards and Patrick, 1965; Falliers, 1970; Palm et al., 1970).

Hospital data are important because they provide the only available indication of trends in morbidity from severe asthma in children. Even if these trends can be explained entirely by changes in medical practice, such an increase in the hospitalisation of young children warrants discussion. The data

Table 1 Annual number of bed-days per $10000^{*}$ due to asthma admissions in the 5-to 14-year age group: NHS hospitals 1960 and 1972

\begin{tabular}{|c|c|c|c|c|c|c|}
\hline & \multicolumn{2}{|l|}{ Boys } & \multicolumn{2}{|l|}{ Girls } & \multicolumn{2}{|l|}{ All } \\
\hline & 1960 & 1972 & 1960 & 1972 & 1960 & 1972 \\
\hline Asthma & $100 \cdot 8$ & $81 \cdot 9$ & 66.4 & $46 \cdot 9$ & $167 \cdot 2$ & $128 \cdot 8$ \\
\hline $\begin{array}{r}\text { Bronchitis }+ \\
\text { pneumonia }\end{array}$ & $158 \cdot 0$ & $40 \cdot 4$ & $135 \cdot 0$ & $29 \cdot 6$ & $293 \cdot 0$ & $70 \cdot 0$ \\
\hline
\end{tabular}

*Estimated annual discharge rate per $10000 \times$ average length of stay. Source: Hospital In-Patient Enquiry.

*Strictly speaking these are hospital discharges and deaths for asthma.

Received 5 July 1977

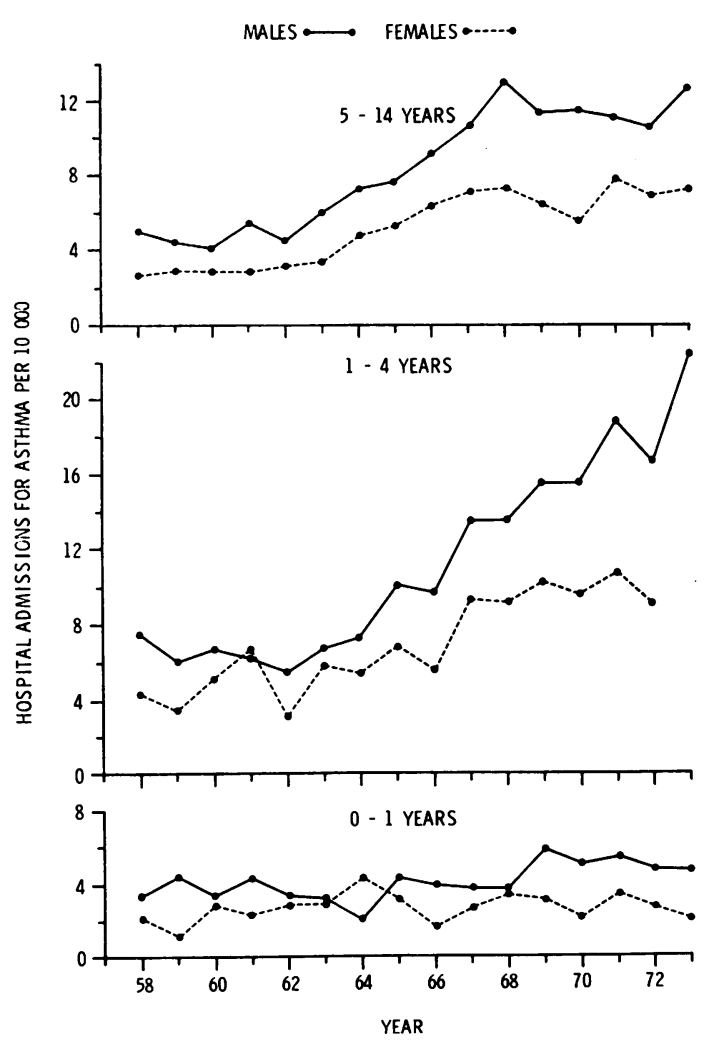

Fig. 1 Hospital admissions for asthma in England and Wales, 1958-73 (source: HIPE). 
available are inadequate to determine precisely the complex factors responsible for this increase. However, it is intended that discussing them within the framework of an appropriate model will help clarify some of the important questions concerning childhood asthma. The model (Fig. 2) shows three factors, therapy, organisation of care, and illness behaviour, as interdependent and to some extent inseparable. Together they determine admission criteria and, by interacting with basic morbidity, produce the level of morbidity observed in the community.

\section{Sources of data}

Trends in admissions for asthma and other childhood respiratory diagnoses were constructed from published and unpublished data from the HIPE. Unpublished regional summaries of the Annual Hospital Return provided information about available paediatric beds and paediatric outpatient attendances. Information about changes in readmission rates and source of referral was obtained by analysis of disease indexes and case notes of asthma admissions aged 5-14 years from two North London suburban hospitals for the periods 1959-63 and 1973-74. Both of these hospitals had shown a more than threefold increase in children's admissions for asthma over this time. To provide additional information about variations in source of referral in 1973-74, case notes from an inner London teaching hospital were examined in the same way. National trends in prescriptions by general practitioners for some antiasthmatic preparations were obtained from the Department of Health and Social Security (DHSS).

\section{Information system}

Classification. The only revision of the International Classification of Diseases (ICD) within the period under discussion occurred in 1965 (implemented by HIPE in 1968). This did not change the criteria for classifying asthma and cannot explain the observed trends.

Diagnostic transfer. Because diagnostic fashions may change over time, and because the clinical diagnosis of asthma is not always clear-cut, it is possible that other respiratory conditions are being increasingly labelled as asthma. For example, 'wheezy bronchitis', 'asthma with bronchitis', and 'asthmatic bronchitis' are all classified under the ICD as 'bronchitis unqualified' (ICD 490). A trend towards the diagnosis of these conditions as 'asthma' cannot be excluded, especially as there is increasing epidemiological evidence that 'wheezy bronchitis' is

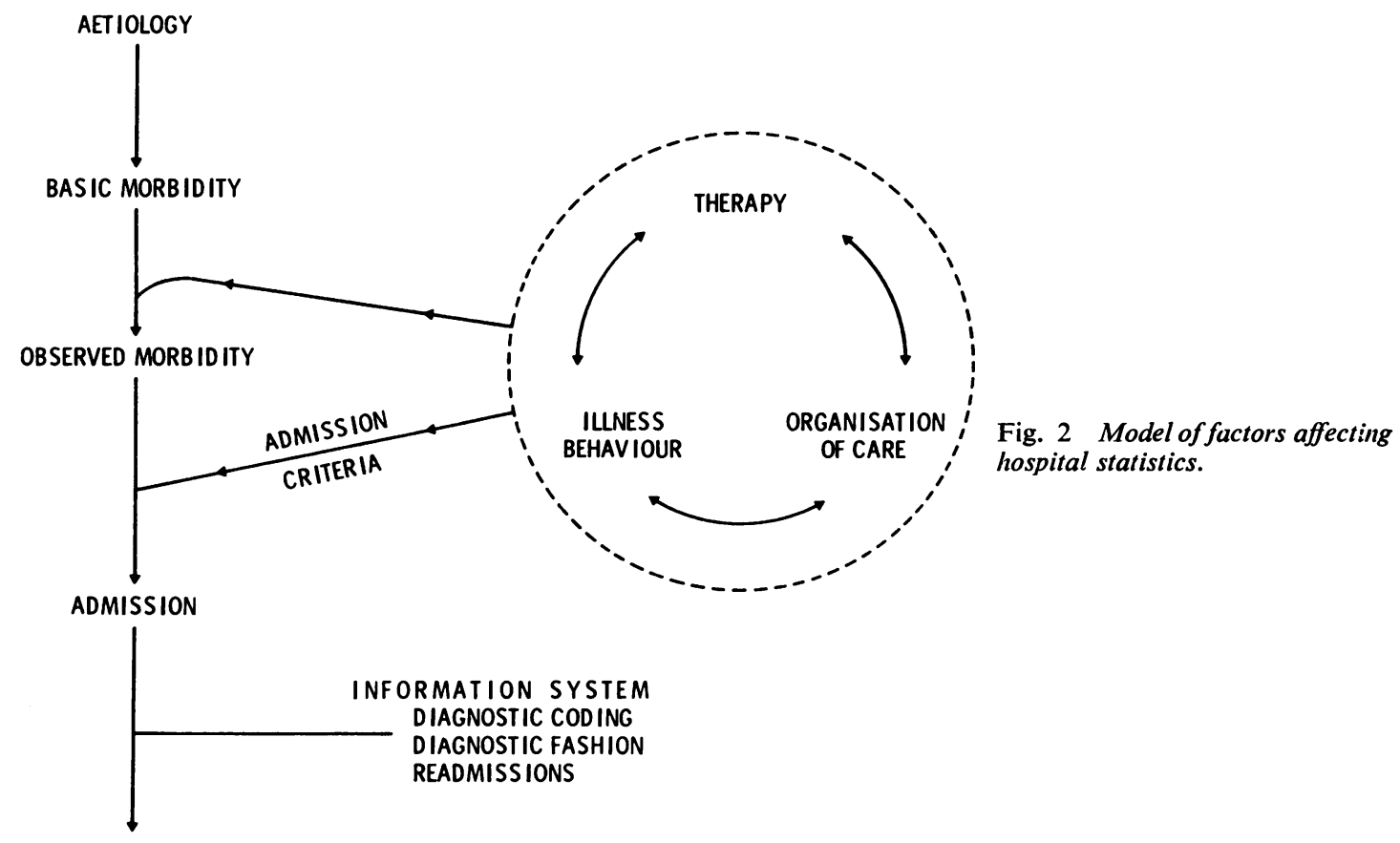

HOSPITAL STATISTICS 
closer to the syndrome of asthma than to acute bronchitis (Williams and McNicol, 1969). A comparative study of case notes is unlikely to settle this question because insufficient diagnostic criteria would be available.

Clues about diagnostic transfer were sought by comparing trends in asthma admissions with those of conditions with which diagnostic transfer may have occurred. From Fig. 3 it appears that neither the direction nor scale of trends in other respiratory conditions is consistent with the theory that diagnostic transfer could account for the nearly threefold increase in asthma admissions.

Readmissions. Since HIPE does not distinguish between admissions and readmissions, the increase in admission rates for asthma could be due either to an increase in the number of patients admitted annually or to an increase in the admissions per patient. A survey of Hospital Activity Analysis disease indexes from 6 hospital groups in different areas of England in 1973-74 showed a calendar year readmission rate (no. readmissions in one calendar year $\div$ total admissions in the same calendar year) of $25 \%$ in the 0 - to 4-year age group and $26 \%$ in the 5- to 14-year age group (Anderson, 1976). Assuming a uniform distribution of admissions throughout the year, these calendar year rates refer to an average of 6 months 'at risk of readmission'. These rates are likely to be underestimates because patients readmitted under another case number or

$$
1 \text { - } 4 \text { YEARS }
$$

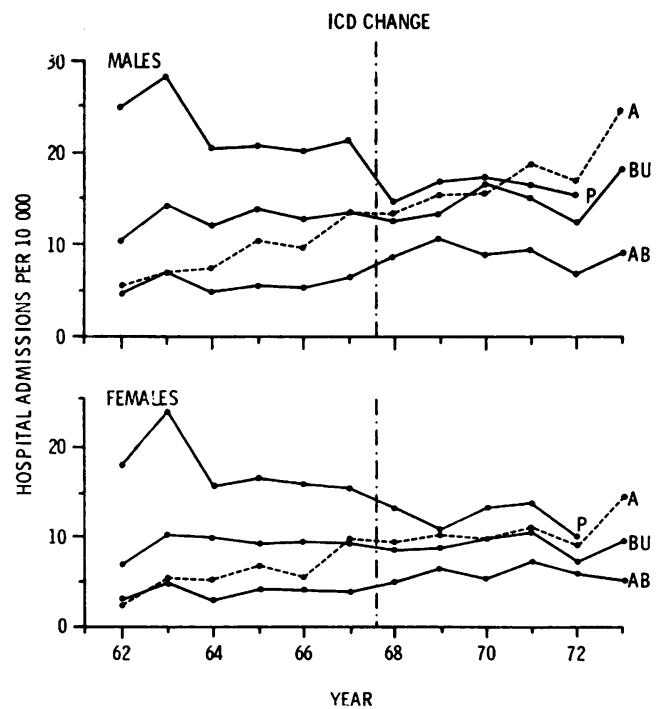

to another hospital would not be identified as readmissions.

Readmission is therefore an important feature of asthma utilisation data and trends in readmissions might explain some of the trends in admissions. At the two London suburban hospitals, calendar year readmission rates for the 5-14 age group in 1959-63 were compared with those in 1973-74. These rose from $11 \%(8 / 73)$ to $27 \%(40 / 148)$ and the proportion of persons admitted more than once within a calendar year increased from $12 \%(8 / 65)$ to $19 \%(21 / 108)$. Readmissions per person readmitted rose from $1(8 / 8)$ to $1.9(40 / 21)$. If these figures represent the national trend, the increase in admissions appear to be partly explained by an increase in readmissions.

\section{Criteria for admission}

Changes in admission criteria may consist of either (a) a change in the distribution of the various reasons for admission, or (b) a change in the level of severity considered to warrant admission for any of these reasons (sometimes referred to as 'threshold'). As Fig. 2 indicates, admission criteria are influenced by the way health services are organised, by the current fashions of therapy, and by the many factors which may be classified under the heading of 'illness behaviour' (Mechanic, 1968).

In asthma the various reasons for admission include degree of acute physical disturbance,

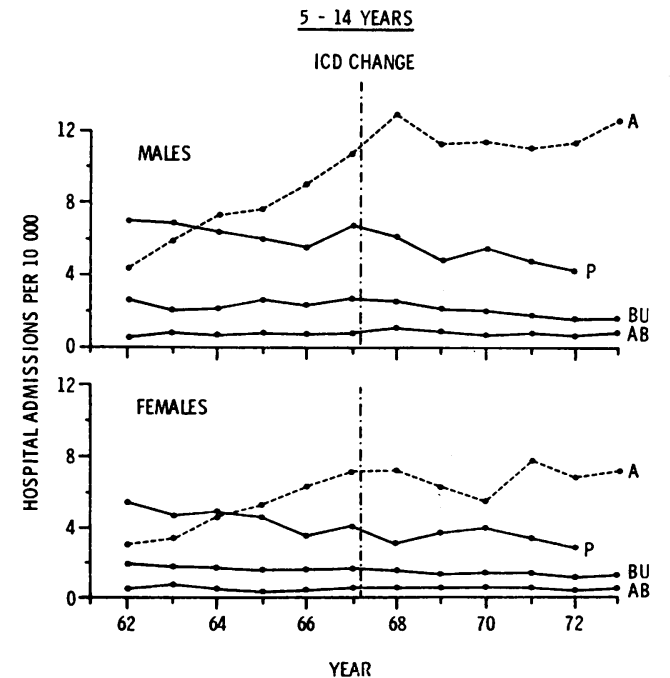

Fig. 3 Trends in admissions for acute bronchiris $(A B)$, bronchitis unqualified $(B U)$, pneumonia $(P)$, and asthma $(A)$ in England and Wales, 1958-73 (source: HIPE). ICD=International Classification of Diseases. 
duration of episode, considered risk of deterioration or death, stabilisation of difficult chronic asthma, investigation, and social and psychological needs. Commonly, a number of these reasons are combined.

It is difficult to obtain evidence for a trend in the distribution of reasons for admission using routine data. However, HIPE records immediate admissions (not booked or planned, waiting list or transfer), thus enabling identification of those admissions likely to have been urgent. Over the period 1963 to 1973, the percentage of immediate admissions increased from $86 \%$ to $92 \%$ in the 5 - to 14-year age group, while remaining at nearly $100 \%$ in the $0-4$ age group $(97 \%$ to $99 \%)$. This suggests that the increase in admissions is not the result of an increase in nonurgent reasons for admission such as stabilisation or investigation.

Although routine data do not now describe any other aspect of admission criteria, such data are required if theories about admission trends which invoke changes in admission criteria are to be tested. One such theory is that the publicity surrounding the increase in asthma deaths among young people in the mid-1960s has resulted in an increase in admissions for less severe asthma. This theory was tested by a case-note study at two London suburban hospitals, in which an attempt was made to measure the changes in acute physical severity of asthma on admission using the temperature/pulse/respiration chart and the notes of the admitting doctor (Anderson, 1976). Among immediate admissions aged 5-14 years, 64 patients from 1959-63 and 86 patients from 1973-74 were compared. The two groups did not differ in terms of pulse rate on admission, average pulse over the first 24 hours, pulse recovery rate, respiratory rate, or length of wheezing before admission. There was no adequate way of validating these criteria; however, if they do indicate acute physical severity, the results are not consistent with the hypothesis that there is a trend towards admitting milder cases.

\section{Organisational factors}

The theoretical structure of the National Health Service referral system has not changed since 1948. Within the system, however, there appears to be considerable flexibility and this may lead to variations in the type of doctor responsible for making admission decisions. It is likely that these different doctors-general practitioners (GP), their locums, emergency relief service doctors, paediatricians, allergy specialists, chest physicians, and casualty officers-will differ in their propensity to admit. Also, the patient (family) may by-pass the GP altogether and present directly to casualty.
The source of referral of immediate admissions in children aged 5-14 years to 3 London hospitals is shown in Table 2. In 1973-74 the main source of referral varied considerably, by hospital, between self-referrals, GP referrals, and outpatient referrals. In the 2 hospitals with high outpatient referral rates, most were from an 'open' paediatric clinic to which the GPs and occasionally the patient (family) could refer without appointment. At one suburban hospital there had been a major increase in self-referrals, from $8 \%$ in $1959-63$ to $62 \%$ in 1973-74. Although these examples may not be typical, they indicate that there are trends and variations in the way decisions concerning asthma admissions are being made.

Admission rates may also reflect the supply of services and it has been shown, for example, that for all medical departments regional admissions correlate well with available medical beds (Logan, et al., 1972). Although there has been no change in the provision of paediatric beds over this time, their relative availability could have increased due to a decline in use for some other paediatric conditions. Even if this were the case, bed provision has probably not been important since regional analysis for 1971-73 found no significant correlation between paediatric asthma admissions and available paediatric beds.

On average, GP referrals of patients with asthma are quite uncommon (inpatient $3 \%$, outpatient $4 \%$; investigation $3 \%$ of patients consulting per year) (Office of Population Censuses and Surveys, 1974). The existence of an accessible and highly regarded service for asthmatics could easily promote a shift in GP referral rates. There are no routine data about the organisation of services for asthmatics or the outpatient activity of asthmatics. However, regional analysis shows that paediatric asthma admission rates for 1971-73 are positively correlated with total paediatric outpatient attendances for $1972(r=0.6$, $\mathrm{df}=13, \mathrm{P}<0.01$ ). This suggests that an increase in outpatient influence over asthmatics might increase

Table 2 Sources of referral of immediate admissions for asthma (discharge diagnosis) from 1959 to 1963 (2 hospitals) and from 1973 to 1974 (3 hospitals) of boys and girls aged 5 to 14 years

\begin{tabular}{|c|c|c|c|c|c|c|c|c|c|}
\hline \multirow{2}{*}{$\frac{\text { Hospital }^{*}}{\mathrm{~A}}$} & \multirow{2}{*}{$\begin{array}{l}\text { Period } \\
1959-63 \\
1973-74\end{array}$} & \multicolumn{2}{|c|}{$\begin{array}{l}G P \\
\text { referred }\end{array}$} & \multicolumn{2}{|c|}{$\begin{array}{l}\text { Self- } \\
\text { referred }\end{array}$} & \multicolumn{2}{|c|}{$\begin{array}{l}\text { Outpatients } \\
\text { referred }\end{array}$} & \multicolumn{2}{|c|}{ Total } \\
\hline & & $\begin{array}{l}28 \\
16\end{array}$ & $\begin{array}{l}(90) \\
(36)\end{array}$ & $\begin{array}{r}3 \\
28\end{array}$ & $\begin{array}{l}(10) \\
(62)\end{array}$ & $\begin{array}{l}0 \\
1\end{array}$ & (2) & $\begin{array}{l}31 \\
45\end{array}$ & $\begin{array}{l}(100) \\
(100)\end{array}$ \\
\hline B & $\begin{array}{l}1959-63 \\
1973-74\end{array}$ & $\begin{array}{l}24 \\
23\end{array}$ & $\begin{array}{l}\text { (67) } \\
\text { (54) }\end{array}$ & $\begin{array}{r}10 \\
9\end{array}$ & $\begin{array}{l}(28) \\
(21)\end{array}$ & $\begin{array}{r}2 \\
11\end{array}$ & $\begin{array}{l}(6) \\
(26)\end{array}$ & $\begin{array}{l}36 \\
43\end{array}$ & $\begin{array}{l}(100) \\
(100)\end{array}$ \\
\hline C & $1973-74$ & 4 & (18) & 9 & (41) & 9 & (41) & 22 & $(100)$ \\
\hline
\end{tabular}

Percentage in parentheses.

*A \& B, North London suburban; C, Inner London teaching. 
asthma admissions. Although this is contrary to the theory and intention that increased outpatient attendance should reduce the need for inpatient care, it is more understandable if one considers the likely difference between GP and hospital doctor in their attitude to admission as an appropriate solution to their patient's needs.

Although there have been important trends in the nature of general practice (DHSS, 1973), current theories are inadequate to relate these trends to the changes in asthma admissions. It is possible, for example, to explain a high referral rate as being either due to proper caution in the face of a capricious condition with a reputation for unexpected death, or, alternatively, as due to the failure of primary care to control the asthma and take responsibility for the patient.

\section{Therapy}

The role of admission in the accepted management of asthma may have changed over this time. As judged from a number of leading articles, an attitude of greater caution has been promoted (British Medical Journal, 1972a, b, 1975) and this may have increased admissions. Changes in drug treatment may also influence admission decisions. For example, previous or current use of steroids is likely to encourage admission for subsequent episodes. Some treatments, such as oxygen, can in most cases be given only in hospital.

Information concerning consumption of drugs for asthma both in and out of hospital is grossly inadequate. Data on GP prescriptions on the National Health Service show two broad therapeutic groups of relevance to asthma. From 1962 to 1975 , prescriptions for 'drugs relaxing bronchial spasm' (Therapeutic code 18) have increased from 5 to 9 million per year. Prescriptions for 'preparations acting locally on the respiratory tract' (Therapeutic code 20) have increased from nothing in 1967 to nearly 2 million in 1975 . This latter category initially consisted of sodium cromoglycate, but since 1972-73 has also included inhaled steroids. Information about trends in the prescription of particular drugs is not released by the DHSS. In any case the prescription analysis is limited by lack of information about diagnosis and age and it would be impossible, for example, to examine overall trends in use of steroids for asthma in various age groups.

A number of qualitative changes in drug therapy have occurred since 1960 , the main ones being (1) longer acting bronchodilators with fewer side effects; (2) introduction of preventive therapy using sodium cromoglycate; (3) a more 'aggressive' approach, particularly with respect to steroid therapy; and (4) a trend towards inhalation as a mode of administration. The efficacy of newer drug therapies has generally been shown by trials. In children, however, the effect of these advances may have been relatively less because inhaled therapy is unsuitable for younger children and is subject to inefficient and inappropriate use (Paterson and Crompton, 1976). Despite this, it is fair to assume that children as well as adults have consumed increasing amounts of more efficacious drugs; all else remaining equal, this should have resulted in a reduction in admission rates.

\section{Illness behaviour}

Patients cannot admit themselves to hospital for asthma, or can do so only with standing permission (Crompton and Grant, 1975). Nevertheless, their own behaviour is important because they can present themselves to casualty departments or they can exert pressure on their GP-gatekeeper. The extent of this factor cannot be assessed, but evidence from the two general practice morbidity surveys (Logan and Cushion, 1958; OPCS, 1974) suggests that there is an increased use of GPs for conditions which were previously tolerated (Crombie, 1974).

\section{Morbidity}

Increased morbidity could be due to an increase in (1) persons with asthma, (2) frequency of episodes, and (3) severity of episodes (intensity and duration). These elements are affected differentially by various aetiological factors and therapy affects the latter two only.

The only reported serial study of schoolchildren supports an increase in persons with asthma (Smith, 1976). Among British-born Birmingham schoolchildren rates for asthma and wheezing had increased from $1.8 \%$ in $1956 / 57$ to $5.5 \%$ in $1968 / 69$ to $6.3 \%$ in 1974/75. Examination of data on the use of GPs from 1955/56 (Logan and Cushion, 1958) and $1970 / 71$ (OPCS, 1974) shows that the annual rate for persons consulting with asthma has increased by $65 \%$ in boys and $47 \%$ in girls (Table 3 ). The scale of this trend has been underestimated because the 1955/56 survey included asthma with mention of bronchitis, whereas the 1970/71 survey did not. Although there are several explanations for this trend, an increase in persons with asthma is one which cannot on present evidence be excluded. An increase in morbidity can also be caused by a decline in the quality or distribution of care. An even more uncomfortable thought is that current therapy, though effective in the short-term, could be having a harmful long-term effect. 
Table 3 General Practice Morbidity Surveys 1955/56* and 1970/71 $\dagger:$ utilisation rates for asthma in children aged 0-15 years

\begin{tabular}{llllll}
\hline & \multicolumn{2}{l}{$\begin{array}{l}\text { Patients consulting } \\
\text { per } 1000\end{array}$} & & \multicolumn{2}{l}{$\begin{array}{l}\text { Consultations per } \\
\text { patient consulting }\end{array}$} \\
\cline { 2 - 3 } \cline { 5 - 6 } Survey year & Boys & Girls & & Boys & Girls \\
\cline { 1 - 2 } $1955 / 56$ & $12 \cdot 3$ & $6 \cdot 4$ & & $3 \cdot 9$ & $5 \cdot 3$ \\
$1970 / 71$ & $20 \cdot 3$ & $9 \cdot 4$ & & $2 \cdot 6$ & $2 \cdot 7$ \\
$\%$ change & +65 & +47 & & -33 & -49 \\
\hline
\end{tabular}

*Logan and Cushion (1958).

tOPCS (1973).

\section{Discussion}

Some of the factors which may have been responsible for the nearly threefold increase in children's admission rates for asthma have been described. The evidence suggests that changes in diagnostic coding and trends in diagnostic fashion are unlikely to be responsible. Although there may have been an increase in readmissions, it is likely that the main increase has been in the number of persons admitted. The reason for this increase cannot be ascertained from available data. Interpretation of trends in admission might be helped by improving the routine collection of data: important areas include record linkage, outpatient activity, source of referral, reasons for admission, standardisation of diagnosis (including a severity grading), and drug analysis by age and diagnosis. However, apart from the doubtful feasibility of such an exercise, its usefulness might still be limited by continuing gaps in information and lack of explanatory theories. Trends in hospital admissions are however sufficient to draw attention to the fact that something important is occurring and it is hoped that they will stimulate hypotheses which can be tested by ad hoc studies.

Priority must be given to investigating trends in the basic morbidity from asthma. One method would be to repeat some early children's respiratory surveys, as done in Birmingham (Smith, 1976). If a rise in morbidity were to be confirmed, two lines of study should be encouraged: (1) to extend aetiological research, particularly with respect to the effects of the changing environment, and (2) to examine the quality of care for asthma and the long-term effects of current management. If, on the other hand, the increase has been caused by a change in the criteria for admission, then these criteria should be debated and the advantages of admission balanced against the harm that hospitalisation may cause to a young child (Douglas, 1975).

I thank Drs A. Adelstein and J. S. A. Ashley for supplying unpublished data from HIPE, and the doctors and records officers who allowed me access to patients' case notes.

\section{References}

Anderson, H. R. (1976). Trends and variations in hospital utilisation for asthma. MSc report. University of London. British Medical Journal (1972a). Deaths from asthma in young people, 1, 459.

British Medical Journal (1972b). Treatment of status asthmaticus, 4, 563-564.

British Medical Journal (1975). Management of acute asthma, 4, 65-66.

Crombie, D. L. (1974). Changes in patterns of recorded morbidity. Benefits and Risks in Medical Care, p. 17. Office of Health Economics, London.

Crompton, G. K., and Grant, I. W. B. (1975). Edinburgh emergency admission service. British Medical Journal, 4, 680-682.

Department of Health and Social Security (1973). General Medical Services: Report of the Joint Working Party, 1973. HMSO, London.

Department of Health and Social Security and Office of Population Censuses and Surveys (Annual). Report on the Hospital In-Patient Enquiry. HMSO, London.

Douglas, J. W. B. (1975). Early hospital admission and later disturbances of behaviour and learning. Developmental Medicine and Child Neurology, 17, 456-480.

Falliers, C. J. (1970). Treatment of asthma in a residential center: a fifteen-year study. Annals of Allergy, 28, 513-521.

Lockwood, E. (1971). Scottish Hospital Morbidity Data 1961-8. Scottish Health Service Studies, No. 20. Scottish Home and Health Department, Edinburgh.

Logan, W. P. D., and Cushion, A. A. (1958). Morbidity Statistics from General Practice, Vol. I. General. Studies on Medical and Population Subjects, No. 14. HMSO, London.

Logan, R. F. L., Ashley, J. S. A., Klein, R. E., and Robson, D. M. (1972). Dynamics of Medical Care. London School of Hygiene and Tropical Medicine, London.

Mechanic, D. (1968). Medical Sociology. Free Press, New York.

Office of Population Censuses and Surveys (1974). Morbidity Statistics from General Practice. Second National Study 1970-71. Studies on Medical and Population Subjects, No. 26. HMSO, London.

Palm, C. R., Murcek, M. A., Roberts, T. R., Mansmann, H. C., Jr., and Fireman, P. (1970). A review of asthma admissions and deaths at Children's Hospital of Pittsburgh from 1938-1968. Journal of Allergy, 46, 257-269.

Paterson, I. C., and Crompton, G. K. (1976). Use of pressurized aerosols by asthmatic patients. British Medical Journal, 1, 76-77.

Richards, W., and Patrick, J. R. (1965). Death from asthma in children. American Journal of Diseases of Children, 110, 4-23.

Smith, J. M. (1976). Prevalence of asthma and wheezing in children. British Journal of Diseases of the Chest, 70, 73-77.

Williams, H., and McNicol, K. N. (1969). Prevalence, natural history and relationship of wheezy bronchitis and asthma in children. An epidemiological study. British Medical Journal, 4, 321-325.

Correspondence to Dr H. R. Anderson, Department of Clinical Epidemiology and Social Medicine, St. George's Hospital Medical School, Cranmer Terrace, London SW17 0RE. 